\title{
INOCULACIÓN IN VITRO DE LA ROYA BLANCA (Puccinia horiana HENNINGS) EN CRISANTEMO (Dendranthema grandiflora TZVELEV) ${ }^{1}$
}

\author{
César Vences-Contreras², Luis Miguel Vázquez-García
}

\begin{abstract}
RESUMEN
Inoculación in vitro de la roya blanca (Puccinia horiana Hennings) en crisantemo (Dendranthema grandiflora Tzvelev). El presente estudio tuvo como finalidad el desarrollar la técnica de inoculación in vitro de la roya blanca, con el objeto de ahorrar tiempo y espacio en la caracterización de los distintos cultivares de crisantemo respecto al grado de susceptibilidad o resistencia a este patógeno. En Tenancingo, Estado de México, en el periodo 2004-2005 se colectaron hojas de crisantemo que presentaban daños por la enfermedad, se desinfectaron para posteriormente inocular las pústulas sobre plantas creciendo bajo condiciones in vitro. El recipiente de cultivo se mantuvo a una humedad relativa alrededor del 95\% y temperaturas entre los 13 y 27 ${ }^{\circ} \mathrm{C}$, bajo condiciones de luz y oscuridad. Los daños por la enfermedad se manifestaron a los 20 días después de la inoculación. Los tratamientos a $17{ }^{\circ} \mathrm{C}$ y oscuridad generaron un mayor número de pústulas $(18,7)$. El diámetro de las pústulas fluctuó entre los $0,71 \mathrm{~mm}$ (tratamientos con $17^{\circ} \mathrm{C}$ y luz) a los $1,79 \mathrm{~mm}$ en los tratamientos con $19^{\circ} \mathrm{C}$ y bajo oscuridad.
\end{abstract}

Palabras clave: Puccinia horiana, Dendranthema grandiflora, inoculación, infección, susceptibilidad a la roya blanca.

\begin{abstract}
Inoculation in vitro of the white rust (Puccinia horiana Hennings) in chrysanthemum (Dendranthema grandiflora Tzvelev). Inoculation in vitro of the white rust was carried out to save space and time in the characterization of several chrysanthemum cultivars regarding the degree of susceptibility or resistance to this pathogen. In Tenancingo, México, in 2004-2005, leaves of chrysanthemum that presented lesions due to this disease were collected and disinfected to inoculate the pustules on plants growing in vitro. The cultures were maintained at about $95 \%$ relative humidity and temperatures of $13-27{ }^{\circ} \mathrm{C}$, under light and dark conditions. Damages by the disease were observed 20 days after the inoculation. The treatments at $17^{\circ} \mathrm{C}$ and dark conditions produced a larger number of pustules (18.7). The diameter of pustules fluctuated between $0.71 \mathrm{~mm}$ in the treatments with $17{ }^{\circ} \mathrm{C}$ and light, and $1.79 \mathrm{~mm}$ in the treatments with $19{ }^{\circ} \mathrm{C}$ and dark conditions.
\end{abstract}

Key words: Puccinia horiana, Dendranthema grandiflora, inoculation, infection, white rust susceptibility.

\section{INTRODUCCIÓN}

El interés económico que ha alcanzado la flor de corte en el mundo la ha convertido en un negocio competitivo. México basa su potencial florícola en las ventajas climáticas y su cercanía a los Estados Unidos, segundo consumidor mundial de flor (Orozco y Mendoza 2003).

\footnotetext{
Recibido: 13 de diciembre, 2006. Aceptado: 31 de enero, 2008. Tesis doctoral.

2 Facultad de Ciencias Agrícolas. Universidad Autónoma del Estado de México, C.P. 50000. Toluca, México. Correspondencia: cvc@uaemex. mx;1mvg@uaemex.mx.
} 
El cultivo de flores en México ocupa una superficie inferior a $0,5 \%$, sin embargo su participación en el valor agrícola nacional ha aumentado, exportando el $10 \%$ al $15 \%$ de su producción (con ventas estimadas en 40 millones de dólares anuales) y el resto destinándolo al mercado interno (INEGI 2007). El Estado de México sobresale como uno de los principales productores de flor de corte: cuenta con una superficie sembrada de 4.945 ha; la delegación regional de Coatepec Harinas, integrada por los municipios de Villa Guerrero, Tenancingo, Zumpahuacán, Malinalco e Ixtapan de la Sal, es la que concentra el $82 \%$ de la superficie total de la entidad productora de flor y ornamentales (Orozco y Mendoza 2003).

Una de las especies en la que se evidencia el creciente desarrollo del sector florícola en México en los últimos años, es el crisantemo (Dendranthema grandiflora Tzvelev.), del que se han introducido un gran número de variedades con características muy diversas, tanto en calidad, tamaño, color y época de cosecha, como en el grado de susceptibilidad y resistencia a enfermedades.

Desde 1993, ha mermado la productividad en cultivos de crisantemo de la zona debido a la enfermedad denominada roya blanca, cuyo agente causal es Puccinia horiana Hennings, reportándose pérdidas hasta del 100\% de las cosechas, la afectación de 150 hectáreas y pérdidas por 5 millones de pesos en ese año. La gravedad que ya se padecía hizo que en julio de 1993 se publicara en el Diario Oficial de la Federación un plan de prevención y/o control de esta enfermedad (Norma Oficial Mexicana NOM-EM-021-FITO-1994, 1994).

Desde la aparición de la roya blanca a nivel internacional, se han establecido medidas de protección (control legal) que impiden el comercio de material enfermo o con sospecha de estarlo, obligando a sustituir cultivos de gran valor por otros de escasa importancia, a cambiar variedades comercialmente superiores por otras inferiores, trayendo como consecuencia cuantiosas pérdidas económicas a productores y distribuidores.

Aunque De Jong y Rademaker (1986) sugirieron que la resistencia del crisantemo a esta enfermedad está generalmente controlada por un solo gen dominante, solo unos cuantos cultivares muestran resistencia a esta enfermedad (Yamaguchi 1981). No existen muchos estudios sobre la reacción de $P$. horiana en las distintas variedades de crisantemo cultivadas en México. Puesto que la roya es un parásito obligado, las telias necesitan ser mantenidas sobre las plantas como inóculo en las pruebas de caracterización. Las pruebas de campo requieren considerable superficie de terreno y tiempo para completar las evaluaciones (Takatsu et al. 2000), y no se reportan procedimientos de inoculación bajo condiciones in vitro que permitan continuar caracterizando los materiales que se cultivan comercialmente, y de las posibles de introducirse, a fin de que se puedan seleccionar los mejores para su pronta adopción por el productor y/o como progenitores base para programas de mejoramiento genético que generen variedades resistentes a este patógeno, acordes a las condiciones de las zonas productoras.

El objetivo de este trabajo fue el desarrollar la técnica de inoculación in vitro de la roya blanca en crisantemo.

\section{MATERIALES Y MÉTODOS}

La investigación se realizó en la Facultad de Ciencias Agrícolas de la Universidad Autónoma del Estado de México, ubicada en Toluca, México en el periodo 2004-2005. Trabajos previos que comprendieron la utilización de pústulas en diferentes etapas de desarrollo como inóculo y su exposición a soluciones desinfectantes por distintos periodos de tiempo, permitieron establecer la metodología empleada en este trabajo.

Se colectaron de la zona florícola de Tenancingo, Estado de México, hojas de crisantemo variedad Polaris White, con daños por la enfermedad del 60 al $80 \%$ en el área foliar, se lavaron con una solución de detergente líquido, se sumergieron en etanol $(70 \%)$ durante 30 segundos, en hipoclorito de sodio $(1,5 \%)$ por cinco minutos y fueron enjuagadas tres veces con agua destilada estéril dentro de la cámara de flujo laminar.

Con un bisturí, y bajo condiciones de asepsia dentro de una cámara de flujo laminar, se rasparon pústulas semi maduras (no eclosionadas) y se colocaron sobre la superficie foliar de las plántulas de Polaris White desarrolladas in vitro (Figura 1a) sobre 

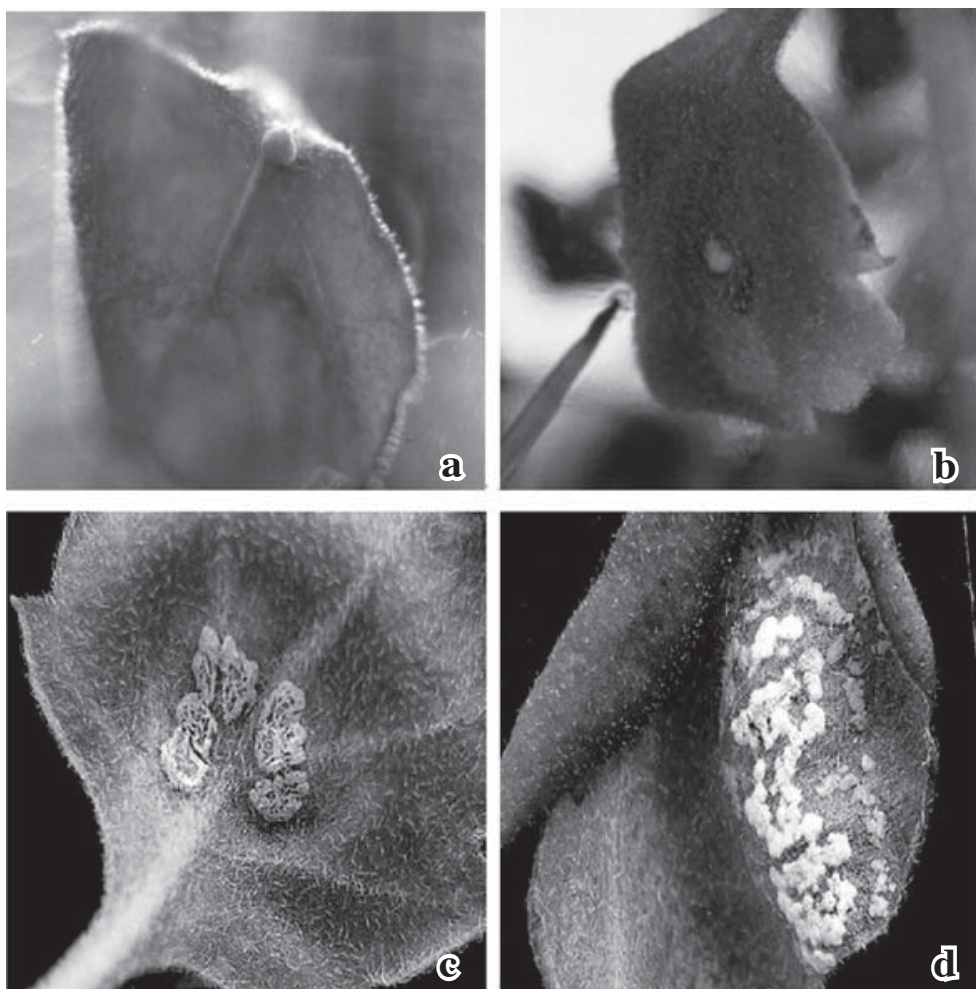

Figura 1. Inoculación y síntomas de la roya blanca (Puccinia horiana) en crisantemo. a) Inoculación in vitro de pústulas semi maduras de Puccinia horiana; b) manchas color verde claro a amarillento de los primeros síntomas de la roya blanca; c y d) formación de pústulas de Puccinia horiana. Toluca, México 2005.

medio MS (Murashige y Skoog 1962) con 1,5 mg/l de kinetina, $0,01 \mathrm{mg} / \mathrm{l}$ de ácido naftalen acético; $30 \mathrm{~g} / \mathrm{l}$ de sacarosa, $\mathrm{pH}=5,6$ y $6,5 \mathrm{~g} / \mathrm{l}$ de agar.

Ensayos previos de inoculación mostraron que colocando los cultivos a una temperatura de $25{ }^{\circ} \mathrm{C}$ -condiciones óptimas para el desarrollo in vitro del crisantemo- solo inducen el desarrollo de micelio, pero no la infección por el hongo. La no existencia de reportes de desarrollo de la enfermedad bajo condiciones in vitro, nos llevó a considerar un amplio rango de temperaturas que cubrieran aquellas en las que se desarrolla el patógeno bajo condiciones de campo.

Se evaluaron ocho rangos de temperatura, entre los $13 \mathrm{y} \operatorname{los} 27^{\circ} \mathrm{C}$ en intervalos de $2^{\circ} \mathrm{C}$ (Cuadro 1). Ocho de los 16 tratamientos se colocaron bajo condiciones de oscuridad por un periodo de 24 horas después de la inoculación para promover la esporulación e infección por basidiosporas (Leyva et al. 2001); los restantes con un fotoperiodo de 16 horas luz y 2000 lux de intensidad lumínica en forma permanente. Una vez concluido el periodo de 24 horas de oscuridad a la que se sometieron los primeros ocho tratamientos, se colocaron bajo las mismas condiciones de luz que el resto. El interior del recipiente de cultivo mantuvo una humedad relativa alrededor del $95 \%$ para favorecer la germinación de teliosporas y basidiosporas (Firman y Martín 1968).

Se evaluó la presencia o no de micelio, daños por la enfermedad, número y diámetro de pústulas. Los datos se analizaron a través del análisis de varianza basado en un diseño experimental completamente al azar y se utilizó el procedimiento de Tukey para la comparación de medias de los tratamientos, empleándose un nivel de significancia $\mathrm{p} \leq 0,05$. 
Cuadro 1. Influencia de la temperatura y la luz sobre la formación de pústulas en la inoculación in vitro de $P$. horiana. Toluca, México 2005.

\begin{tabular}{cccccc}
\hline $\begin{array}{c}\text { Trata- } \\
\text { miento } \\
*\end{array}$ & $\begin{array}{c}\text { Temp. } \\
\left({ }^{\mathbf{0}} \mathbf{C}\right)\end{array}$ & $\begin{array}{c}\text { Luz/ } \\
\text { Osc }\end{array}$ & $\begin{array}{c}\text { Desarrollo } \\
\text { micelial }\end{array}$ & $\begin{array}{c}\text { Número } \\
\text { de } \\
\text { pústulas }\end{array}$ & $\begin{array}{c}\text { Diámetro } \\
\text { de pústulas } \\
(\mathbf{m m})\end{array}$ \\
\hline I & 13 & osc & 0 & 0 & 0 \\
II & 13 & luz & 0 & 0 & 0 \\
III & 15 & osc & 0 & 0 & 0 \\
IV & 15 & luz & 0 & 0 & 0 \\
V & 17 & osc & 0 & 18,7 & 0,88 \\
VI & 17 & luz & 0 & 5,6 & 0,71 \\
VII & 19 & osc & 0 & 5,4 & 1,79 \\
VIII & 19 & luz & 0 & 10,98 & 1,12 \\
IX & 21 & osc & 1 & 0 & 0 \\
X & 21 & luz & 1 & 0 & 0 \\
XI & 23 & osc & 1 & 0 & 0 \\
XII & 23 & luz & 1 & 0 & 0 \\
XIII & 25 & osc & 1 & 0 & 0 \\
XIV & 25 & luz & 1 & 0 & 0 \\
XV & 27 & osc & 1 & 0 & 0 \\
XVI & 27 & luz & 1 & 0 & 0 \\
\hline
\end{tabular}

* 0 ausencia; 1 presencia (para la variable desarrollo micelial)

\section{RESULTADOS Y DISCUSIÓN}

Los síntomas de la roya blanca se manifestaron a los 20 días después de la inoculación. Manchas color verde claro a amarillento aparecieron en el haz de la hoja, en el envés se formaron pústulas color bancoamarrillento que posteriormente se tornaron de un color rosado (Figura 1a). Bishop y Trolinger (1993), Norman et al. (1995), Strider (1995) reportan los mismos síntomas bajo condiciones de campo.

Los tratamientos sometidos a temperaturas de los $13^{\circ} \mathrm{C}-15^{\circ} \mathrm{C}$ no manifestaron síntomas por la enfermedad (Cuadro 1), sin embargo, el borde de las hojas mostraron una ligera necrosis como daño aparente por temperatura.

Las hojas de los tratamientos a $17^{\circ} \mathrm{C}$ generaron 5,6 pústulas en presencia de luz y 18,7 pústulas cuando se mantuvieron en oscuridad por 24 horas después de la inoculación. Los tratamientos a $19{ }^{\circ} \mathrm{C}$ presentaron
10,98 pústulas en presencia de luz y 5,4 pústulas en oscuridad (Figura $1 \mathrm{c}, \mathrm{d}$ ). El diámetro de las pústulas fluctuó entre los $0,71 \mathrm{~mm}$ (tratamiento con $17^{\circ} \mathrm{C}$ y luz) a los $1,79 \mathrm{~mm}$ en los tratamientos con $19^{\circ} \mathrm{C}$ y oscuridad (Cuadro 1), coincidiendo con Firman y Martin (1968) quienes reportan temperaturas óptimas de $17^{\circ} \mathrm{C}$ y la OEPP/EPPO, 2004, entre los $17^{\circ} \mathrm{C}$ y $21^{\circ} \mathrm{C}$ bajo condiciones de campo para la germinación de teliosporas y basidiosporas del patógeno.

Los tratamientos entre los $21-27^{\circ} \mathrm{C}$ presentaron solo desarrollo de micelio sin infección, independientemente de la presencia o no de luz (Cuadro 1). Estos datos no coinciden con los reportados por Takatsu et al. (2000), quien describe temperaturas de $20-25{ }^{\circ} \mathrm{C}$ como apropiadas para la germinación de teliosporas y basidiosporas del patógeno.

El efecto de la luz sobre la germinación de las teliosporas fue poco significativo, como sugieren los estudios realizados por Yamada (1956). El tiempo requerido para este proceso, fue de 20 días después de la inoculación del patógeno, en contraposición al requerido en las evaluaciones en campo como los trabajos realizados en México por Norman et al. (1995), Sandoval et al. 1997 y Vázquez et al.2000, que al realizar evaluaciones comparativas de resistencia de distintas variedades de crisantemo a la roya blanca, emplearon periodos de cuatro meses. La técnica de cultivo in vitro permite, además de un ahorro en espacio y tiempo, el reproducir las respuestas de campo en plantas de crisantemo para evaluar su susceptibilidad a la roya blanca.

Los análisis de varianza para un diseño completamente al azar y la comparación de medias por el método de Tuckey detectaron diferencias altamente significativas y como mejor tratamiento el de $17^{\circ} \mathrm{C}$ y oscuridad, para la variable número de pústulas y al de $19^{\circ} \mathrm{C}$ en presencia de luz para la variable diámetro de pústulas (Cuadro 1).

Este procedimiento desarrollado en Polaris White se implementó a otras 16 variedades de crisantemo con buenos resultados, logrando de esta manera la caracterización de los mismos respecto al grado de susceptibilidad a la roya blanca. 


\section{LITERATURA CITADA}

Bishop, AL; Trolinger, J. 1993. Chrysanthemum white rust (Puccina horiana). Yoder Brothers, Inc. Ala, Fl. U.S.A. 4 p.

Jong, J. de; Rademaker, W. 1986. The reaction of crhysanthemum cultivars to Puccinia horiana and the inheritance of resistance. Euphytica 35: 945-952.

Firman, ID; Martin, PH. 1968. White rust of chrysanthemums. Annals of Applied Biology. 62: 429-442.

INEGI (Instituto Nacional de Estadística, Geografía e Informática) 2007. Anuario Estadístico de Comercio Exterior de los Estados Unidos Mexicanos 2006. Instituto Nacional de Estadística, Geografía e Informática. Edición 2007. 637 p.

Leyva, MSG; Lora, TI; Cárdenas, SE; Valdovinos, PG. 2001. Pathogensis of white rust Puccinia horiana Henn. on a Chrysanthemum [Chrysanthemum morifolium (Ramat) Henns. Susceptible variety]. Revista Mexicana de Fitopatología 19(2): 191-196.

Murashige, T; Skoog, F. 1962. A revised medium for rapid growth and bioassays with tobacco tissue cultures. Physiol Plant. 15: 473-497.

Norma Oficial Mexicana NOM-EM-021-FITO-1994. 1994. Por la que se establece con carácter obligatorio la campaña de prevención y acción contra la enfermedad denominada Roya Blanca del Crisantemo. 12 p.

Norman, MT; García, FA; Sandoval, RFT; Vázquez, GLM; Aquino, MJ; Corona, RMC; Pedral, M.E. 1995. Comparative evaluation of the resistance of 18 chrysanthemum (Dendranthema grandiflora Anderson) varietes to white rust (Puccinia horiana Henn.). Revista Chapingo. Serie Horticultura 1(3): 113-18.
OEPP/EPPO (European and Mediterranean Plant Protection Organization). 2004. Puccinia horiana. European and Mediterranean Plant Protection Organization. Bulletin 34: 209-211.

Orozco, HME; Mendoza, MM. 2003. Competitividad local de la agricultura ornamental en México. Ciencia Ergo Sum. 10(1): 29-42.

Sandoval, RFR; Norman, MT; Corona, RMC; Aquino, MJ; Vázquez, GLM; García, FA. 1997. Determination of damage level caused by Puccinia horiana Henn. on 15 chrysanthemum cultivars (Dendranthema grandiflora Tzvelev.) grown in México. Fitopatología 32(3): 160165.

Strider, DL. 1995. La roya blanca del crisantemo. Una revisión. Rev. Chapingo, Serie: Horticultura 1 (3): 109-112.

Takatsu, Y; Ohishi, K; Tomita, Y; Hayashi, M; Nakajima, M; Akutsu, K. 2000. Use of chrysanhemum plantlets grown in vitro to test cultivar susceptibility to white rust, Puccinia horiana P. Hennings. Plan Breeding. 119: 528-530.

Vázquez, G.L.M; Gloria E.L; Pérez M.L; 2000. Antifungical compound in chrysnthemum (Dendranthema grandiflora Tzvelev.). Fitopatología 35(1): 50-58.

Yamada, S. 1956. Experiments on the epidemiology and control of chrysanthemum white rust, caused by Puccinia horiana P. Henn. Ann. Phytopath. Soc. Japan. 20: 148-154.

Yamaguchi, T. 1981. Chrysanthemum breeding for resistance to white rust (Puccinia horiana). Japanese journal of breeding 31(2): 121-132. 